\title{
O ASSALTO DO CAPITAL FINANCEIRO À EDUCAÇÃO PÚBLICA
}

\author{
EL ASALTO DEL CAPITAL FINANCIERO A LA EDUCACIÓN PÚBLICA
}

\section{THE ASSAULT OF FINANCIAL CAPITAL ON PUBLIC EDUCATION}

\author{
DOI: http://dx.doi.org/10.9771/gmed.v11i3.33974
}

Enrique-Javier Díez-Gutiérrez ${ }^{1}$

\begin{abstract}
Resumen: El artículo analiza cómo el capital financiero está introduciéndose en la educación pública aprovechando los recortes en la financiación de la misma con la excusa de la crisis. Describe diferentes estrategias de esta infiltración a través de reformas educativas neoliberales y de estrategias de patrocinio empresarial o filantropoeducación. Para el capital financiero la educación mundial representa el último gran mercado, un "suculento pastel" al que no está dispuesto a renunciar. Surge así la "Global Education Industry".
\end{abstract}

Palabras clave: Privatización educativa; políticas educativas neoliberales; filantropoeducación; Global Education Industry.

Resumo: O artigo analisa como o capital financeiro está sendo introduzido na educação pública, aproveitando os cortes em seu financiamento com a desculpa da crise. Descreve diferentes estratégias dessa infiltração por meio de reformas educacionais neoliberais e estratégias de patrocínio ou filantropoeducação empresarial. Para o capital financeiro, a educação mundial representa o último grande mercado, um "bolo suculento" do qual você não está disposto a desistir. Assim surge a "Indústria Global de Educação".

Palavras-chave: Privatização educacional; políticas educacionais neoliberais; filantropoeducação; Indústria Global de Educação.

Abstract. The article analyzes how financial capital is being introduced in public education by taking advantage of the cuts in its financing with the excuse of the crisis. It describes different strategies of this infiltration through neoliberal educational reforms and business sponsorship or philanthropoeducation strategies. For financial capital, world education represents the last great market, a "succulent cake" that you are not willing to give up. Thus arises the "Global Education Industry".

Key-words: Educational privatization; neoliberal educational policies; philanthropoeducation; Global Education Industry.

Vivimos una época de dictaduras económicas donde el genocidio y la barbarie se perpetran desde los cómodos despachos de Wall Street y el Ibex 35 (índice de referencia de la bolsa española). Asistimos a la unanimidad de grupos políticos conservadores, neoliberales, ultraderechistas e incluso socialdemócratas sobre la supuesta insostenibilidad del Estado de bienestar en pleno siglo XXI. Se pelean por competir en esta loca carrera para ver quién adelgaza y suprime más todos los sistemas de protección y solidaridad que afectan a la mayoría, para salvaguardar el sistema financiero y las leyes del mercado, manteniendo, eso sí, un aparato policial y represivo cada vez más amplio, difuso y sólido que contribuye a aplastar cualquier atisbo de disidencia o contestación.

Pero vivimos no solo una guerra económica, donde el saqueo de los recursos colectivos se ha vuelto obsceno y criminal, sino que asistimos simultáneamente a una guerra ideológica, irregular y asimétrica, 
que ampara y justifica dicho saqueo y lo normaliza. En esta guerra ideológica la batalla por la narrativa es clave en la fabricación de una determinada percepción de la realidad (posverdad), de cara a imponer imaginarios colectivos impregnados de contenidos, significados y emociones afines al pensamiento dominante. Y el papel de los sistemas educativos en la construcción de esta narrativa es determinante para el lobby neoliberal.

Esta narrativa se centra en cuestionar, minimizar y recortar el papel del Estado y las responsabilidades de las instituciones públicas respecto a la protección de lo que fueron los derechos sociales y la defensa de lo común y público y en reprimir cualquier forma de organización colectiva que pueda desafiar el estado de las cosas. Suele racionalizarse y presentarse como "libertad" —especialmente "libertad económica"- y se envuelve en el lenguaje del individualismo y la inversión personal como ventaja competitiva. Exalta la iniciativa privada y el mercado promoviendo la "cultura del emprendimiento" que culpabiliza a las propias víctimas y a las personas empobrecidas de su suerte.

El neoliberalismo ha desencadenado una poderosa batalla teórica, o sea, política, contra
los principios y las razones que justifican proyectos colectivos y universales y contra la
constitución de sentidos y motivos compartidos que nos ayuden a cimentar sociedades
más igualitarias y justas. Poner lo común bajo sospecha, identificando toda aspiración a
construir lo que nos pertenece y nos iguala como comunidad, esto es, lo público, como
la causa de todos nuestros males y penurias, ha sido una de las mayores victorias del
liberalismo de la segunda mitad del siglo XX (GENTILI, 2011, 22).

De esta forma, reemplaza el concepto de "bien común" por el de "responsabilidad individual", convirtiéndonos en consumidores y clientes, sustituyendo así el antiguo contrato social de la comunidad por la "ley del mercado". Desregulación, liberalización y privatización se han convertido, de esta forma, en los instrumentos estratégicos de la política económica que el programa neoliberal elevó a ideología decretada por los Estados.

Este discurso neoliberal ha inundado todos los rincones del planeta. Los medios de comunicación de la era ciberelectrónica están imponiendo la adoración unánime de los valores de la sociedad neoliberal. Una monocultura que destruye los valores y las culturales locales e incluso integra los elementos contestatarios vendiéndolos como parte del paquete global. En todas partes se manejan las mismas informaciones y noticias, se ven las mismas películas, se conducen los mismos automóviles, se imponen las mismas modas, se escuchan las mismas canciones y se soportan los mismos anuncios publicitarios, generando una uniformidad hostil a la diversidad cultural del planeta.

A imagen de este modelo económico y social neoliberal se está construyendo una educación neoliberal. El marco de referencia de esta educación neoliberal no es la sociedad democrática, sino el mercado capitalista. Sus planteamientos, su orientación, sus propuestas y prácticas están destinadas a dar respuesta fundamentalmente a este mercado.

Hemos de entender que la primera premisa básica que fundamenta esta ideología neoliberal es que, cual rey Midas, todo lo que toca lo convierte en negocio, en búsqueda de beneficios, de dividendos, de dinero, de "oro". Y los derechos humanos, los derechos sociales y culturales, los derechos colectivos también pueden ser fuente de negocio si se privatizan y empiezan a operar en el marco del sistema de mercado. 
El capitalismo persigue el beneficio, éste es su objetivo principal. Por ello necesita crecer continuamente y obtener más beneficio. Es como una bicicleta, que si se deja de dar pedales se derrumba. El problema, es que el capitalismo, como un virus, se ha extendido por todo el globo y por todos los ámbitos del planeta, convirtiendo en negocio todos los aspectos de la vida. Ya no le quedan prácticamente nuevas fronteras, otros espacios que conquistar geográficamente. La última frontera, el último "far west" que le quedaban por asaltar son los bienes comunes, lo público y, sobre todo, los servicios sociales que proporciona el Estado. Una fuente inagotable, puesto que son básicos, necesarios y esenciales para todos los seres humanos de todo el planeta, de forma continua.

Para el capital financiero la educación mundial representa el último gran mercado, un fabuloso tesoro y éste es un "suculento pastel" al que no está dispuesto a renunciar. Surge así la "Global Education Industry", que no solo tiene que ver con la privatización de la educación sino con la concepción neoliberal de que la educación es el medio clave para el desarrollo de la competitividad y el éxito individual y, por lo tanto, los gobiernos, las escuelas y universidades, las familias y los propios estudiantes están cada vez más dispuestos a invertir su dinero en educación y en productos y servicios relacionados con la educación orientados a mejorar los resultados de los estudiantes (Lingard \& al., 2017).

Este nuevo mercado no se asalta inmediatamente, sino que se ha generado un proceso sutil y progresivo que va adquiriendo pequeñas partes del "pastel", pero también del sentido común, porque necesita seducir y convencer para ir avanzando, poco a poco, coordinando apropiaciones y discursos.

Este fenómeno tiende a transformar el sistema educativo mismo. Los efectos se manifiestan no solo en las desigualdades entre el alumnado (quien puede y quien no se lo puede pagar, quién va a los grupos o centros de "excelencia" y quién es segregado en los "itinerarios basura"), sino también en el contenido de los conocimientos (se valoran las materias más rentables en términos económicos de promoción profesional y social, se centra la enseñanza en alcanzar los mejores resultados de los exámenes estandarizados); en el desarrollo de mentalidades jerárquicas, consumistas y competitivas; en las formas de aprendizaje (método mecánico, comprensión superficial, culto a la eficacia y a la rapidez). Se pone así en marcha una "verdadera industria" de la educación y la formación, creando auténticos mercados educativos impulsados por los principios de la denominada "libre elección" (que realmente es preferencia de selección para que mis hijos y mis hijas no estén con los que no son de su misma clase social) y la competición (que construye simbióticamente el nuevo sujeto neoliberal, el emprendedor).

Las reformas educativas neoliberales que se imponen en todo el planeta buscan, por una parte, reducir el período de enseñanza obligatoria. Es decir, apuestan por la exclusión de una cierta parte de quienes han sido incluidos, en el último medio siglo, en el proceso de escolarización creciente de la población en los países del norte. Mediante estrategias que están siendo reforzadas: la potenciación de exámenes o pruebas de paso de un nivel, etapa, ciclo o curso a otro, y el reforzamiento de las exigencias para promocionar de uno a otro, fortaleciendo así el carácter selectivo, incluso en los niveles obligatorios; la consolidación de itinerarios o ramas paralelas a edades cada vez más tempranas; la segregación en forma de grupos de clase según capacidades; la consagración oficial de diversas redes de centros docentes en función de la clase social o de determinadas características personales como el sexo o la confesión religiosa; y el establecimiento de 
diferenciaciones competitivas relevantes entre centros docentes de un mismo nivel, etapa o ciclo obligatorio - centros de excelencia, bilingües, etc. Estrategias que se ven acompañadas simultáneamente de la reformulación del principio de gratuidad, mediante la extensión de los conciertos o subvenciones a la enseñanza privada, la implantación de los cheques escolares y de formación, las deducciones fiscales del coste de la matrícula en los centros privados y el incremento de las tasas de matrículas en los centros públicos de los niveles educativos no obligatorios con el fin de dificultar el acceso a los mismos, introduciendo sistemas de re-pago, aduciendo que es necesario asumir la "responsabilidad" del coste real de la educación.

Por otra parte, las reformas educativas neoliberales buscan también aumentar la diferenciación de las dos redes de educación. No se trata de que el sector público desaparezca, sino que se centre en atender, sobre todo, a las clases bajas, migrantes y minorías, así como alumnado con necesidades educativas o con dificultades de aprendizaje, es decir, a quienes sean rechazados por el sector privado o no hallen acomodo en el mismo, y también en dar servicio en aquellas zonas, como las rurales, que no son rentables para la iniciativa privada. Permanecerá así la Educación Pública como una red subsidiaria de la privada, de cuya financiación se desentienden progresivamente los poderes públicos, con progresivos recortes, reduciendo el número de profesorado e incrementando el número de alumnado por profesor, las horas lectivas del profesorado y las materias consideradas afines con vistas a su enseñanza por un mismo profesor; la desaparición o reducción de programas de refuerzo o apoyo, desdobles y atención a la diversidad, tutorías, materias optativas, módulos de formación profesional, servicios de orientación o biblioteca, ayudas para adquisición de libros de texto, comedores y actividades extraescolares, etc. Recortes acompañados, ante las protestas del profesorado, de una campaña de descrédito del mismo y de los sindicatos que las promueven o apoyan.

Mientras, se fomenta el proceso de privatización educativa, mediante la creación de centros de enseñanza privada y la potenciación de su demanda. Las reformas apuestan también por la implicación de "proveedores no gubernamentales" (como lleva recomendando la OCDE desde 1987) facilitándoles la construcción y creación de centros privados mediante la cesión de suelo público, o la adjudicación directa a empresas de la explotación de centros públicos. Pero utilizan otras vías que apuntan a la expansión de las opciones privadas: la creación de zonas únicas de escolarización (eliminando el criterio de proximidad y de distribución equilibrada de todo el alumnado a la hora de la matriculación), la ampliación de los criterios de los centros privados financiados públicamente para seleccionar a su alumnado, el establecimiento de mecanismos para financiar públicamente más tramos de la enseñanza privada como la educación no obligatoria o las desgravaciones fiscales para quienes lleven a sus hijos e hijas a colegios privados. Surge así un nuevo mercado en expansión: la "filantropoeducación” que está "amazonizando" buena parte del actual sistema educativo, y donde los multimillonarios, fundaciones y bancos "filantrópicos" ya no están detrás de la donación y el patrocinio, sino que pasan a dirigir y gestionar las donaciones bajo variables de mercado, diseñar las propias políticas educativas y orientar el destino de las "inversiones" realizadas, aunando capitalismo y filantropía con más mercado como solución a los problemas educativos.

La necesidad de fondos económicos en los centros educativos públicos, debido a los recortes en la financiación a la educación, y la sutil penetración en la mentalidad colectiva del mantra de la «colaboración 
público-privada», está abriendo cada vez más el campo al patrocinio empresarial de los centros escolares. Esta forma de privatización va apareciendo, cada vez con más frecuencia, también en los centros públicos, a través de diferentes formas y estrategias: la financiación de instalaciones a cambio de publicidad encubierta o explícita en las mismas; la dotación de recursos o materiales a los centros con sus logotipos de marca impresos; el patrocinio empresarial y de bancos de concursos con supuesta finalidad educativa o de formación competitiva «ligada a la realidad»; la dotación de premios al «mejor profesor o profesora» por multinacionales del edunegocio; o incluso la promoción y publicidad de supuestas reinvenciones de «innovación educativa», que, más bien, son un remake de propuestas pedagógicas clásicas, pero que se venden en «charlas TED», difundidas profusamente en redes sociales, como «soluciones milagrosas a la educación» y como «nuevo pensamiento positivo educativo».

En EE.UU., la UE, Latinoamérica, Asia o Australia la venta de espacio publicitario en las escuelas y universidades se ha disparado a lo largo de las últimas décadas: en las paredes exteriores e interiores de los centros, en los autobuses escolares, en las páginas de las revistas del alumnado e incluso en los libros de texto escolares. La dependencia respecto a las financiaciones publicitarias se muestra especialmente sensible en los centros escolares de zonas periféricas y más empobrecidas, allí donde la financiación de las escuelas es demasiado escasa para hacer frente a las necesidades educativas. Muchas escuelas e institutos se dejan seducir por las propuestas de actividades o de materiales «didácticos» elaborados por las empresas y las marcas para aumentar sus recursos pedagógicos. Obtienen así, a cambio de un anuncio publicitario o del patrocinio de una actividad, ordenadores, mobiliario y a veces incluso nuevos materiales deportivos o, más modestamente, la reparación de la pintura en las aulas o en el centro.

Una de las últimas tendencias de este patrocinio empresarial son los premios a los mejores profesores o profesoras. El Global Teacher Prize es un galardón financiado por la Fundación Varkey, fundada por el empresario de la educación Sunny Varkey, quien dirige GEMS Education, la mayor cadena de colegios privados del mundo, un negocio con grandes beneficios. Este premio promueve la potenciación de una visión de «profesor emprendedor estrella», olvidando que la educación es una construcción colectiva y no el logro individual y esforzado de un solo profesor o profesora, por muy buen docente que sea.

Este modelo de exaltación de la figura de un profesional determinado, convierte en espectáculo y competición la profesión docente y poco hace por mejorar las condiciones materiales de la docencia en todo el mundo, celebrando al «héroe» o «heroína» que, en condiciones de adversidad y recortes, es capaz de salir adelante, ocultando la responsabilidad de la política pública en cambiar esas condiciones. Es más, lo que tiende es a redefinir el rol del profesorado hacia la espectacularización y el reality show de «superdocentes» (superhéroes o superheroínas con «métodos estrella» únicos), que se convertirán en reclamos comerciales para los centros o consorcios vinculados, en un contexto de cada vez mayor competitividad por atraer a la nueva «clientela». Este enfoque contribuye así a dar una imagen equivocada de en qué consiste la docencia y el trabajo cotidiano en los centros, realizado en equipo por el profesorado y la comunidad educativa, lo cual poco o nada tiene que ver con un galardón individual (Barnes, 2018).

Otra reciente estrategia de privatización y mercantilización de la educación es la denominada filantropoeducación o filantropocapitalismo educativo (Frumkin, 2006; Bishop \& Green, 2008; Saltman, 
2010; Saura, 2017a; Worth \& Lambert, 2019). «En las fallas de los gobiernos, los filantrocapitalistas entienden que es el momento idóneo para incorporar sus éxitos de capital debido a la extensión de la crisis por todo el globo y los consecuentes procesos de escasez de inversión en las políticas sociales. En el caso de la educación, los filantrocapitalistas logran incorporarse con gran preponderancia en la arena política al comprender que pueden dedicarse a la caridad a la vez que extienden los límites del mercado» (Saura, 2017b: 34). Avanzando así hacia una nueva «filantropía neoliberal» que promueve la expansión de las relaciones de mercado.

Como describe Saura (2017b), el Banco Mundial y la Unesco son defensores de estas nuevas alianzas híbridas de gobernanza. Fundaciones que penetran cada vez más en las estructuras de gobierno e institucionales, que ejercen una fuerte influencia en los cambios políticos de los sistemas educativos hacia una mayor privatización educativa y una mayor profundización en el modelo neoliberal del sistema educativo. Lo privado y lo público, como resultado de la incorporación del filantrocapitalismo a la política pública, son espacios cada vez más difuminados (Williamson, 2018).

Esta gobernanza híbrida global invierte no solo los términos de las relaciones y los equilibrios de poder, donde el Estado y el sistema educativo pasan a ser dependiente y subsidiado por la voluntad y caridad de los donantes, sino que pervierte también la concepción de lo que debe ser un sistema impositivo que comparta las cargas y redistribuya los recursos. Parece como si ahora debiéramos depender de las donaciones filantrópicas, que no solo están liberadas y tienen exenciones de impuestos, sino que dan además «buena imagen de marca» a la empresa (Imbernon, 2017).

$\mathrm{Si}$ en lugar de establecer donaciones «caritativas», que siempre dependen de la voluntad del donante, se legislara una adecuada financiación de las necesidades educativas y sociales, mediante una fiscalidad progresiva y una subida de impuestos a las grandes fortunas y a los extravagantes beneficios del capital, las arcas públicas no estarían saqueadas y los representantes públicos de la sociedad, elegidos democráticamente, y los profesionales de la educación serían los que podrían decidir sobre la adecuada distribución en función de las necesidades y prioridades, y no en función de los caprichos o intereses estratégicos, de imagen o marketing comercial de los multimillonarios.

En paralelo se aplican y extienden medidas de privatización de la red pública mediante la introducción de técnicas de gestión de la empresa privada en la dirección y organización de los centros educativos, que se consideran más eficaces y medibles con sus indicadores de resultados, lo cual permite establecer sistemas de "rendición de cuentas" y "rankings comparativos", así como la gestión "flexible" desde la dirección/gerencia de los "recursos humanos" (lo cual se ha facilitado extraordinariamente con las reformas laborales) o el establecimiento de fórmulas contractuales (contratos-programa) de "gestión por objetivos" y "pago por resultados" para la financiación y sostenimiento de los centros (dar más a las escuelas o al profesorado que mejores resultados académicos obtienen). Medidas de comercialización que avanzan en la utilización de los centros por empresas privadas que llevan a cabo actividades lucrativas complementarias en horario escolar o fuera del mismo; el fomento de la financiación externa (publicidad, alquiler de locales, patrocinio privado, máquinas expendedoras de productos, etc.) que convierten al centro docente en un espacio más comercial que educativo; la externalización o subcontratación de actividades extraescolares, 
comedores, incluso la formación del profesorado, la evaluación de los centros o la construcción y mantenimiento de edificios escolares o la introducción dentro del currículo académico y del horario lectivo de personal privado, precarizado y en condiciones laborales que cada vez erosionan más los derechos y las condiciones de todo el plantel educativo.

Los argumentos para esta "guerra ideológica" desatada por los sectores políticos neoliberales y neoconservadores, que gobiernan, son los mismos que se aplican a todos los servicios públicos: defendemos la "libertad de elección" del consumidor (que, insisto, es preferencia de selección); lo público es ineficaz y tenemos que establecer mecanismos de control de resultados y rendición de cuentas (con incentivos y pago por resultados, como si en educación se pudiera contabilizar exactamente a quién se le puede asignar el resultado de un proceso educativo); lo privado supuestamente surge de la "iniciativa social" (como si las empresas o las corporaciones fueran sociedad civil) y apoyarla es satisfacer "la demanda social" (como si la educación fuera un producto que se compra en un gran supermercado); la reducción de gastos sociales son ajustes necesarios para garantizar los servicios y derechos sociales, para mantener un servicio público sostenible, etc.

Por eso, la reconstrucción de otro tipo de sociedad requiere no sólo necesarias e imprescindibles luchas, propuestas, reivindicaciones y acciones concretas, directas y a corto plazo. Son batallas cruciales. Pero hemos de pensar también en la "guerra ideológica global" en la que estamos inmersos. Y esta guerra ideológica exige simultáneamente un planteamiento estratégico fundamental a más largo plazo: la necesidad de deconstruir la genealogía de los "valores" neoliberales dominantes en la que nos han "educado" y la imprescindible tarea de entusiasmar y comprometer con "valores" y concepciones solidarias a toda la ciudadanía y, especialmente, a las nuevas generaciones. Es aquí, en el campo de batalla de la educación donde se libra la lucha estratégica y esencial, y es aquí donde también se han de concentrar fuerzas.

La pregunta es, por tanto, ¿cómo ofrecer alternativas a las nuevas generaciones en otra forma de pensar que no esté colonizada por el pensamiento neoliberal único del capitalismo?

Se trata del modelo de educación que queremos, la política educativa que se debe desarrollar, los contenidos esenciales que queremos transmitir a las futuras generaciones. Se trata de analizar al servicio de quién se diseñan, a quién favorece y qué tipo de sociedad ayudan a construir. Porque, en definitiva, cualquier práctica educativa cotidiana tiene que ver esencialmente con las cosmovisiones y las estructuras económicas y políticas actuales. La responsabilidad de las personas educadoras no puede separarse de las consecuencias del conocimiento que producen, las relaciones sociales que legitiman y las ideologías que diseminan.

La educación es un proyecto de desarrollo de las personas como ciudadanos y ciudadanas partícipes activamente en el proyecto político, económico y cultural de la sociedad en la que viven. Es un proyecto para la democracia y la ciudadanía. Y eso supone la imposible separación entre educación y práctica política. A pesar de la concepción de la derecha conservadora y neoliberal que identifica con adoctrinamiento cualquier indicio de política que no sea la suya.

Pero el problema no es si la educación pública ha llegado a contaminarse con la política, sino que la educación es ya un espacio de la política y el poder, lo queramos o no. 
La educación crítica es una pedagogía de resistencia frente a la doctrina neoliberal, pero también de proyección de alternativas y experiencias educativas que hagan posible pensar la educación desde otros parámetros diferentes. Una educación comprometida con la equidad y la comprensividad, que concibe la educación como un derecho que el Estado debe garantizar para todas y todos, que lucha por hacer realidad escuelas democráticas e inclusivas que eduquen para una ciudadanía mundial intercultural comprometida con una visión profeminista alternativa a la cultura patriarcal.

Estamos actualmente ante una grave disyuntiva. Hoy dos proyectos ideológicos, sociales y políticos avanzan a nivel mundial. Estos dos proyectos encarnan dos formas radicalmente diferentes de entender el ser humano, las relaciones económico-sociales y la educación.

El primero, asienta sus raíces en un modelo económico y social capitalista basado en el egoísmo competitivo y fundamentado en la ideología neoliberal. Para esta ideología el interés colectivo no tiene por qué ser la finalidad la política educativa. Aboga por un mundo de competición descarnada, donde el mercado regule quién sobrevive en esta lucha permanente y desaparezcan los mecanismos de protección del bien común. Parte del axioma, según el cual, las personas son responsables individualmente de su posible bienestar o malestar. Depende únicamente del mérito y del esfuerzo propio lo que se consigue en la vida. Sólo los más aptos sobrevivirán, puesto que los débiles y pobres no han sabido o querido esforzarse lo suficiente para triunfar. La pobreza y la desigualdad son inevitables, y, en todo caso, algo se puede paliar con misericordia, sean obras de caridad, fundaciones u ongs. Apuesta por un programa educativo estandarizado, exclusivo y socialmente regulativo que sirve a los intereses del poder dominante y de aquel alumnado íntimamente ligado con los estándares sociales y culturales que se asocian con dicho poder.

Este modelo neoliberal, a pesar de la desigualdad mundial creciente que ha provocado, sigue siendo defendido por sus adeptos. Ha conseguido convertir la educación, de un derecho garantizado, en una oportunidad de negocio de corporaciones empresariales y grupos de intereses (en España, ligados fundamentalmente a la jerarquía católica), e impone cada vez con mayor ahínco un modelo de gestión de las escuelas selectivo como si fueran empresas que exigen "rentabilidad "y beneficios.

Con este modelo queda en el olvido un fundamento básico para la educación, que no es otro que procurar el progreso de todos y de todas y no el de unos pocos. Este es el otro modelo, que tiene un objetivo democrático, inclusivo y sensible con los aspectos sociales y la equidad. Que considera que la finalidad de la educación es favorecer el desarrollo personal intelectual, moral, socio afectivo y psicomotor de cada estudiante; educar personalidades libres, con amor y gusto por el saber, con independencia de juicio y creativas, corresponsables de la vida de las demás personas y de la sostenibilidad del planeta; formar una ciudadanía activa, crítica, solidaria, democrática y comprometida con la mejora de la sociedad en la que viven. Busca la mejora de todas las escuelas públicas y hacerlas aceptables a las familias, en vez de incitarlas a elegir y competir, ya que no solo es menos costoso, sino que preserva los fines sociales de la educación. Entiende la educación como un bien común, en el que las familias participen, no como clientes, sino como copartícipes activos en la construcción social de una escuela beneficiosa para sus hijos y los hijos e hijas de los demás. 
Concebir la educación como un derecho impone a los Estados y a los Organismos Internacionales la obligación de garantizar a todos los habitantes del planeta la oportunidad de cubrir sus necesidades básicas de aprendizaje. Eso significa que, tal como estableció el Foro Mundial para la Educación de Dakar de 2000, todo gobierno está obligado a asegurar una buena educación básica, pública y gratuita, de modo que no se puede rehusar a ningún niño ni a ninguna niña el acceso a la educación porque no pueda pagarla.

La obligación de la comunidad, por tanto, debe ser garantizar el derecho a la mejor educación que tienen todas las personas, por el hecho de ser personas, al margen de cualquier otra condición. Y eso solo es posible con una red pública única, que no derive recursos públicos de nuestros impuestos a financiar opciones privadas, que garantice una oferta de plazas públicas suficientes en todos los niveles y modalidades educativas desde los 0 años, que respete criterios pedagógicos y equitativos que beneficien a los menores y que ofrezca igualdad de oportunidades no solo de acceso, sino también durante el proceso educativo y al finalizarlo.

Sólo una escuela pública, con titularidad, gestión y financiación públicas, puede garantizar a todas las personas una educación en esas condiciones de igualdad, especialmente para quienes menos posibilidades tienen de obtenerla de otra forma. La Educación Pública es la única que garantiza la equidad y la cohesión social respetando el derecho de cada uno y cada una a lograr el nivel máximo de formación y educando en un proyecto común de ciudadanía.

Es más, los tratados internacionales de la ONU y la UNESCO y la mayoría de las Constituciones nacionales establecen que la educación es un derecho universal que debe ser garantizado mediante un Sistema Público de Educación, de titularidad y gestión pública, como eje vertebrador y fundamental del sistema educativo, que permita garantizar el derecho a la educación en condiciones de igualdad, sin ningún tipo de discriminación de origen social o cultural, o por razones de creencias, de sexo, de orientación sexual o cualesquiera otras características de índole personal.

Las evidencias internacionales demuestran en definitiva que la escuela pública es la única garantía de este derecho universal a la educación en condiciones de igualdad y democracia, es la que más y mejor asegura la igualdad y la convivencia democrática de personas con distintas procedencias socio-culturales; y por ello, es la que mejor contribuye a la equidad y la cohesión social. Además de ser la única que se compromete con el interés común y el servicio público, al margen de intereses particulares ligados al adoctrinamiento ideológico o al negocio económico.

Por eso debemos apostar por un Sistema de Educación Pública con una financiación blindada constitucionalmente, de tal forma que ningún gobierno, sea del signo político que sea, pueda sustraer los recursos públicos destinados a la educación para pagar los intereses de deudas, o a los banqueros e inversores que las gestionan, antes que destinarlos a asegurar este derecho fundamental a toda la población. Como dice el que fuera durante veinte años Rector de la Universidad de Harvard, Derek C. Bok, "si usted cree que la educación es cara, pruebe con la ignorancia". Ya expresaba esta convicción de forma contundente el famoso dramaturgo Víctor Hugo afirmando “cada vez que se abre una escuela se cierra una cárcel”. También porque es lo más "rentable” que puede hacer una sociedad. El Nobel de Economía James Heckman decía que por cada euro invertido por niña/o el rendimiento es de entre el 7 y el 10\% anual a lo largo de su vida. Es decir, 
que cada euro invertido en educación inicial revierte en ocho euros del producto social en las etapas posteriores, una rentabilidad mucho mayor que la de los fondos de inversión, añadía irónicamente. De ahorrar, ¿no habría que empezar por priorizar el ahorro en armamento, o bienes de lujo o rescates a bancos antes que en educación?, o si la cuestión son los ingresos ¿no tendríamos que aumentar la recaudación fiscal de las grandes fortunas y de los paraísos fiscales, para tener una educación pública digna y suficiente?

De ahí que sea urgente reconstruir, tanto en el discurso cotidiano del "sentido común", como en los programas políticos, una concepción de la educación como derecho público y como bien común. Para impedir que educación se convierta cada vez más en una mercancía, es necesario imponer un repliegue de los intereses privados y de la ideología de la gestión empresarial que actualmente avanzan en la colonización de la educación con el discurso neoliberal.

Solo así seremos capaces de pensar y ayudar a construir y consolidar una sociedad con un horizonte pos-capitalista, pos-colonial o pos-imperialista y pos-patriarcal. No debemos olvidar que, en la sociedad contemporánea, los tres factores principales que están en la base de la dominación social, política y cultural son: el capitalismo (explotación del trabajo asalariado), el colonialismo (relación jerárquica entre grupos humanos) y el patriarcado (relación de poder basada en la inferioridad natural de un sexo o de una orientación sexual). Por eso hemos de avanzar simultáneamente en modelos educativos postcapitalistas, postcoloniales y postpatriarcales, en el sentido de que superen y abandonen definitivamente estas estructuras de opresión y dominación y avancemos hacia un modelo educativo que contribuya al éxito escolar de todo el alumnado y a la formación de personas más iguales, más libres, más críticas y más creativas.

Si somos capaces de imaginar la posibilidad de viajar a Marte, de conseguir vacunas contra diferentes tipos de cáncer, de que podremos crear robots y ser optimistas en conseguirlo, sabiendo que es cuestión de destinar recursos para avanzar en esas líneas de investigación y ser constantes hasta conseguirlo, por qué aceptamos con tanta resignación la imposibilidad de erradicar el hambre y la pobreza, de hacer desaparecer el fascismo o de tener la mejor educación para todas y cada uno de las personas que habitan el planeta. Como en los primeros casos, es cuestión de destinar los recursos necesarios para ello y tener voluntad política constante para poner los medios hasta conseguirlo.

Lucio Anneo Séneca, en el siglo IV antes de nuestra era, afirmaba: "no nos atrevemos a hacer muchas cosas porque aseguramos que son difíciles, pero son difíciles porque no nos atrevemos a hacerlas". Nos jugamos el futuro de nuestros hijos e hijas, y el de la sociedad en su conjunto. Como diría Sábato (2000), “estamos a tiempo de revertir esta masacre. Esta convicción debe poseernos hasta el compromiso...". Educación o barbarie, no hay neutralidad posible. Tenemos que atrevernos a soñar.

\section{Bibliografía}

BARNES, H.G. (2018). El Confidencial. Un español puede convertirse en el mejor 'profe' del mundo, y quizá sea mala noticia. [Recuperado de https://goo.gl/3dRrTq]

BISHOP, M. \& GREEN, M. (2008). Pbilanthropocapitalism. How Giving Can Save the World. London: Bloomsbury Press. 
FRUMKIN, P. (2006). Strategic giving: the art and science of philanthropy. Chicago: The University of Chicago Press.

GENTILI, P. (2011). Pedagogía de la igualdad. Ensayos contra la educación excluyente. Buenos Aires: CLACSO Siglo XXI Editores.

IMBERNON, F. (2017). La nueva filantropía. Responsabilidad Social Corporativa de las empresas en el funcionamiento de los centros escolares. ¿Aportación o beneficio? Organización y Gestión Educativa, 3, 20-22.

LINGARD, B.; SELLAR, S.; HOGAN, A. \& THOMPSON, G. (2017). Commercialisation in Public Schooling (CIPS). New South Wales Teachers Federation: Sydney, NSW.

SÁBATO, E. (2000). La resistencia. Barcelona: Seix Barral.

SALTMAN, K, (2000). Collateral Damage. Corporatizing Public Schools - A Threat to Democracy. Lanham: Rowman and Littlefield Publishers.

SAURA, G. (2017a). Filantropía, corporaciones y gobiernos neoliberalizando desde los centros educativos. Organización y Gestión Educativa, 3, 24-28.

SAURA, G. (2017b). ¿Crisis? ¿Qué crisis? Filantrocapitalismo, neoliberalización y gobernanza en la política educativa global. Nuestra Bandera, 236, 32-43.

WILLIAMSON, B. (2018). Silicon startup schools: technocracy, algorithmic imaginaries and venture philanthropy in corporate education reform. Critical Studies in Education, 59(2), 218-236.

WORTH, M. J., \& LAMBERT, M. T. (Eds.). (2019). Advancing Higher Education: New Strategies for Fundraising, Philanthropy, and Engagement. Rowman \& Littlefield Publishers.

\section{Notas:}

${ }^{1}$ Doctor en Ciencias de la Educación. Licenciado en Filosofía. Diplomado en Trabajo Social y Educación Social. Ha trabajado como educador social, como maestro de primaria, como profesor de secundaria, como orientador en institutos y como responsable de atención a la diversidad en la administración educativa. Actualmente es Profesor de la Facultad de Educación de la Universidad de León. Especialista en organización educativa, desarrolla su labor docente e investigadora en el campo de la educación intercultural, el género y la política educativa. Orcid: http://orcid.org/0000-0003-3399-5318 Email: ejdieg@unileon.es 